\title{
Involving disabled children and young people as partners in research: a systematic review.
}

Short title: Involving disabled children and young people as partners in research

Sarah Bailey BSc (hons) $\mathrm{MPH}^{1}$

Kate Boddy BA MA MSc ${ }^{2}$

Simon Briscoe MSc MCLIP ${ }^{3}$

Christopher Morris MSc DPhil ${ }^{4}$

1 Associate Research Fellow, Peninsula Cerebra Research Unit, University of Exeter s.e.r.bailey@exeter.ac.uk

2 Associate Research Fellow, Patient and Public Involvement Team, PenCLAHRC k.boddy@exeter.ac.uk

3 Information Specialist, Peninsula Technology Assessment Group, University of Exeter s.briscoe@exeter.ac.uk

4 Senior Research Fellow, Peninsula Cerebra Research Unit, University of Exeter christopher.morris@exeter.ac.uk

Correspondence:

Christopher Morris

PenCRU, Child Health Group

University of Exeter Medical School

Veysey Building

Salmon Pool Lane

EX2 4SG

UK

For submission to Child: Care, Health and Development

Word count: 2498

Key words: children, disabled, young people, disabled children and young people, involvement, participation, consultation, research, methodology. 


\section{ABSTRACT}

\section{Background}

Children and young people can be valuable partners in research, giving their unique perspectives on what and how research should be done. However, disabled children are less commonly involved in research than their non-disabled peers. This review investigated how disabled children have been involved as research partners; specifically how they have been recruited, the practicalities and challenges of involvement and how these have been overcome, and impacts of involvement for research, and disabled children and young people.

\section{Methods}

The INVOLVE definition of involvement and the Equality and Human Rights Commission definition of disability were used. Relevant bibliographic databases were searched. Websites were searched for grey literature. Included studies had involved disabled children and young people aged 5-25 years in any study design. Reviews, guidelines, reports and other documents from the grey literature were eligible for inclusion.

\section{Results}

Twenty-two papers were included: seven reviews, eight original research papers, three reports, three guidelines and one webpage. Nine examples of involvement were identified.

Recommendations included developing effective communication techniques, using flexible methods that can be adapted to needs and preferences, and ensuring that sufficient support and funding is available for researchers undertaking involvement. Positive impacts of involvement for disabled children included increased confidence, self esteem and independence. Positive impacts for research were identified.

\section{Conclusions}

Involving disabled children in research can present challenges; many of these can be overcome with sufficient time, planning and resources. More needs to be done to find ways to involve those with non-verbal communication. Generally, few details were reported about DCYP's involvement in studies, and the quality of evidence was low. Although a range of positive impacts were identified, the majority of these were authors' opinions rather than data. There remains scope for methodological research to inform appropriate approaches to public and patient involvement in childhood disability research.

Word count: 300 


\section{Introduction}

Increasingly, children and young people (CYP) are being involved in health research as partners in the research process, and directly consulted for their views and opinions.(Allsop et al. 2010, Kirk 2007, Clavering and McLaughlin 2010a) Public and Patient Involvement (PPI) is defined by INVOLVE (2014) as:

"research being carried out 'with' or 'by' members of the public rather than 'to', 'about' or 'for' them".

This shift is associated with the recognition that children have the right to be involved in decisions that concern them,(Coad and Shaw 2008, Coad J and Evans R 2008) and growing awareness that involving CYP can benefit research and young people.(Curtin 2001, Barker J and Weller S 2003)

Disabled children and young people (DCYP) have been less commonly involved in research,(Beresford 2012, Kembhavi and Wirz 2009, Morris J 2003) perhaps because of perceived difficulties with access, communication, and negative assumptions about their abilities.(Clavering and McLaughlin 2010a, Allsop M et al. 2011, Beresford B 2012) Involving disabled children in research is vitally important; they are ideally placed to say what works and how things can be better for themselves and their families.

Involving DCYP in the research process is likely to be beneficial, but presents methodological challenges.(Germain R 2004) There is little guidance on best practice and few examples of research projects that have successfully involved DCYP. Involvement is often poorly defined, and methods inadequately reported. Some studies report activities with DCYP as 'involvement' even if the children are subjects in the research.

The Peninsula Cerebra Research Unit carries out PPI with families of DCYP.(Morris et al. 2011, McHugh et al. 2013) To date this has been achieved successfully with parents (see www.pencru.org). Methods to involve DCYP are now being explored within the unit. The aims of this review were:

1. To find out how DCYP have been accessed, recruited or selected for involvement in research projects.

2. To investigate how the practicalities of involving DCYP in research have been addressed.

3. To identify the challenges of involving DCYP in research and how have these been overcome.

4. To describe the impacts of involving DCYP in research on the disabled children themselves.

5. To describe the impacts of involving DCYP in research on the research.

\section{Methods}

\section{Public and patient (family) involvement}

Six parents of disabled children were involved in this review; setting the research questions, defining the inclusion and exclusion criteria, identifying and screening websites, and interpreting the results of the review. Due to differences in time commitments, not all parents were involved in all of these ways. The group were supported by the research team to undertake these tasks and received a $£ 25$ 
acknowledgement of their time for each half day worked, in addition to travel and childcare expenses.

\section{Search strategy}

Health and social care databases were searched to identify literature for the review. The searches combined the terms "child", "participation" and "disability". Synonyms and Medical Subject Headings were identified using different search terms with the aim of ensuring an appropriate balance of sensitivity and specificity. The search strategy initially only used search terms for "child" and "participation" but the search results were considered to be too sensitive and high in number so search terms for "disability" were added. Generic terms for disability were used alongside several terms for more common conditions, given the complications of trying to list every possible disability.

Databases searched included: MEDLINE (Ovid); MEDLINE-in-process (Ovid); CINAHL (EBSCO); ASSIA (ProQuest); Cochrane Database of Systematic Reviews; DARE (via Cochrane) (see appendix 1 for full details of search strategies for each database). Results were limited to English language papers and date limited to 1990.Forward and backward citation chasing was carried out on included papers to supplement the database searches. In addition, relevant websites were searched (appendix 2).

\section{Study selection}

The search aimed to find any study design in which DCYP were reported as being involved as partners in research, or reviews that had addressed this type of involvement. Peer reviewed papers were sought, alongside guidelines, reports or other documents from the grey literature. Studies must have involved DCYP aged 5-25 as partners in health research in one of the acknowledged approaches to involvement.(INVOLVE 2013) A non-categorical approach was taken; the Equality and Human Rights Commission definition of disability (1995) was used:

'a physical or mental impairment which has a substantial and long-term adverse effect on his ability to carry out normal day-to-day activities. Examples include cancer, diabetes, multiple sclerosis and heart conditions; hearing or sight impairments, or a significant mobility difficulty; and mental health conditions or learning difficulties'

Titles and abstracts were screened by two authors (SB and KB). Full text articles were retrieved for 61 papers. These results were assessed for inclusion independently by the same two authors (SB and $\mathrm{KB})$; where there was uncertainty or disagreement, a third author was consulted (CM).

\section{Data extraction}

Data were extracted using a standardised data extraction form by one reviewer (SB) and checked by another (KB). Authors were contacted for clarification where certain details of involvement were missing. Study quality was assessed using a modified CASP qualitative checklist (CASP 2013). Data were extracted and organised in themes corresponding to each objective to be addressed in the review, with documents of different types grouped together. The findings for each theme were 
summarised, with similarities, differences and patterns identified across the data, and to integrate key themes to address the research objectives.

\section{Results}

Twenty-two documents were included in the review (figure 1); seven review articles, eight original research papers, three reports, three guidelines and one webpage (table 1). Nine documents included examples of involvement (table 2). Four documents had been produced in partnership with DCYP. Only two papers reported research evidence about involvement; one interviewed DCYP who had been involved in research about their experiences and opinions (Lightfoot and Sloper 2003) and the other reported results from surveys of successful examples on involvement with DCYP (Sloper and Lightfoot 2003).

The DCYP involved in these nine examples of involvement were aged 10-21 years. Four projects included a specific condition (diabetes, asthma, HIV, autistic spectrum disorder). Funding sources included government agencies and charities.

The overall methodological quality of studies was low, but low quality studies were included where they reported an example of involvement with DCYP. This is because it was the example of involvement that was relevant to this review, not the overall study. It was difficult to evaluate the quality of the examples of involvement due to few details being reported in papers. Papers based on authors' opinions were included; although of comparably low quality, this information was relevant.

\section{How have DCYP been accessed, recruited or selected for involvement in research?}

DCYP had been accessed through schools, hospitals, in the community, and online. Methods of advertising involvement opportunities included Internet forums, websites, newsletters and direct mailing. Partner organisations, youth workers and school staff were also used to reach young people. Some involvement opportunities required DCYP to volunteer directly to get involved, but one project required parents to get in touch on behalf of their child.(Mogensen 2010) Only one project used a structured recruitment and selection process.(VIPER 2013)

Guidance recommends providing clear explanations of exactly what the DCYP are being asked to get involved in, using appropriate language in a variety of formats.(Lightfoot and Sloper 2003, Street and Herts 2005)

\section{How have the practicalities of involving DCYP in research been addressed?}

Practical recommendations include ensuring venues are fully accessible to meet the needs of participants,(Allsop et al. 2010, Kirby 2004, Morris 2003) appropriate timings with regular breaks, providing refreshments and sufficient time/support.(Street and Herts 2005, VIPER 2013) Specific recommendations for sessions include using engaging activities likely to be enjoyable, interesting and appropriate to age and/or ability,(Cavet and Sloper 2004) and incorporating flexibility to be inclusive of different abilities,(Cavet and Sloper 2004) and considering offering choices about activities.(Lightfoot and Sloper 2003, Mogensen 2010) A range of methods for involving DCYP have been reported previously. (Lightfoot and Sloper 2003) Payment, vouchers, outings or social occasions have been used to acknowledge and thank DCYP for their time.(Lightfoot and Sloper 2003, VIPER 
2013) Funding for the additional costs associated with providing support for DCYP to participate should be secured before recruiting.(Kirby 2004)'(Shaw et al. 2011)

\section{What challenges have been faced by others in involving DCYP in research, and how have these challenges been overcome?}

\section{Access and communication}

Anticipating and meeting the communication and access needs of DCYP presents a significant challenge to involvement; DCYP need effective ways of communicating with each other, and with research staff.(Allsop et al. 2010, Clavering and McLaughlin 2010b) A lack of suitable aids can result in those who use non-verbal communication being excluded.(Cavet and Sloper 2004) Drawing, photography, talking mats, cue cards, pictures and tape recordings have been used to engage DCYP who use non-verbal methods of communication.(Shaw et al. 2011, Clavering and McLaughlin 2010b) A trusted adult or familiar communicator can be useful to facilitate and support communication.(Beresford 2012) Research staff require sufficient time, resources, skills and training to facilitate successful involvement.(Sloper and Lightfoot 2003, Street and Herts 2005, Cavet and Sloper 2004, Delman 2012)

\section{Experience and balance of power}

Researchers need to balance the DCYPs' right to participate in research with a responsibility to protect them and ensure they are not overburdened.(Mogensen 2010) Sensitive meeting content may cause distress,(Beresford 2012) and it may not be possible to guarantee confidentiality in project meetings.(Street and Herts 2005) Researchers should also consider how ongoing support can be provided after meetings.(Beresford 2012) A lack of confidence(Delman 2012, Street and Herts 2005) feeling intimidated by professionals or unfamiliar working environments, (Street and Herts 2005)'(Delman 2012) unrealistic expectations of involvement,(Sloper and Lightfoot 2003) not feeling routinely listened to,(Lightfoot and Sloper 2003) perceptions of tokenism,(Street and Herts 2005) or being unused to giving their opinion(Kembhavi and Wirz 2009, Mogensen 2010) can all hold DCYP back from getting involved in research. Faced with challenges they feel they cannot face, they may lose confidence or interest in the project.(Delman 2012)

These challenges have been addressed by empowering DCYP to take control over the research agenda and methods,(Mogensen 2010) define their own and others' roles in the project,(Mogensen 2010, VIPER 2012) allowing them to raise issues that are important to them,(Street and Herts 2005) being transparent if a certain option is not possible,(Lightfoot and Sloper 2003, VIPER 2013) and always giving feedback on the outcomes of involvement.(Lightfoot and Sloper 2003, Street and Herts 2005) DCYP may take on more responsibilities as their confidence grows.(VIPER 2013) (Delman 2012)

\section{Gatekeepers}

Gatekeepers include parents, carers, hospital and school staff, who can act as a facilitator or barrier to involvement. Gatekeepers may discourage, prevent or forget about involvement,(Mogensen 2010, Morris 2003) respond on behalf of their child if attending meetings,(Cavet and Sloper 2004) give their own view,(Delman 2012) interrupt the flow of communication or prevent DCYP from 
feeling able to speak their minds.(Mogensen 2010) Parental anxiety around explaining or exploring their child's disability may hinder involvement.(Allsop et al. 2010)

Gatekeepers should be fully informed of their roles and responsibilities.(Mogensen 2010) Parents can provide invaluable information about DCYP's needs,(Shaw et al. 2011) but DCYP with no parents to advocate for them are at increased risk of being excluded from involvement opportunities.(Cavet and Sloper 2004)

\section{What are the impacts, positive and negative, of involving DCYP in research on the DCYP, and on the research?}

Positive impacts of involvement on DCYP are numerous, and engaging DCYP can have an impact at all stages of the research process; both positive and negative impacts were identified (figure 2).

\section{Discussion}

This review collated recommendations for involving disabled children as partners in research; however we identified few well-reported examples. The importance of developing effective communication methods when involving DCYP in research was a common theme among papers identified by the review, particularly for those with non-verbal communication.(Shaw et al. 2011, Delman 2012, Cavet and Sloper 2004) Flexible methods that can be adapted to individual need is recommended for overcoming challenges of involvement.(VIPER 2012, Delman 2012, Street and Herts 2005)

The involvement of parents of DCYP in this study was particularly strong. Parents determined the direction of the review alongside the staff researchers, contributed to screening websites, gave their opinions on the results and their importance, and will contribute to a plain language summary of this review.

The quality of evidence identified by this review is low, but no studies were excluded due to quality. Reporting involvement was the primary focus for only one study.(Beresford 2012) Others reported involvement in varying levels of detail as part of a wider study and challenges and impacts of involvement were rarely reported. Few details were given about involvement and limitations of involvement were not commonly evaluated. Many of the impacts of involvement reported in the literature are based on authors' opinions and experiences, although one study interviewed DCYP about impacts of involvement for them.(Lightfoot and Sloper 2003)The GRIPP checklist aims to help researchers and service users improve the reporting of involvement,(Staniszewska et al. 2011) but it is often not possible to include details of involvement in a paper.

Defining the search strategy was particularly challenging in this review due to inconsistencies in how involvement is defined and reported, and an inability to capture all terms that may refer to a disability or medical condition. The term 'involvement' is used to describe research on and with children, and the phrase 'research with children' has been used to describe both DCYP as partners(Beresford 2012, Clavering and McLaughlin 2010b) and participants.(Clavering and 
McLaughlin 2010b) A wide definition of disability was adopted for this review, but some relevant examples of involvement with DCYP with less common conditions could have been missed. The majority of papers included were UK or USA based; relevant examples from other countries may not have been identified due to the English language limitation on this study or because involvement is described differently in other countries. Over $75 \%$ of papers concerning public involvement in health research have originated in the UK or USA.(Boote et al 2012).

This review found a range of information to support the involvement of DCYP in research, and several examples of successful involvement. Flexible methods are essential to support the involvement of DCYP and their impact on research, while maintaining power and control over how and when they are involved. Few studies involved DCYP with non-verbal communication; more effective ways of engaging with this group must be developed.(Clavering and McLaughlin 2010b) There was little evidence concerning impacts of involvement, financial costs of involvement, involvement of DCYP from minority ethnic groups, and those with the most complex disabilities. There remains much scope for methodological research to inform appropriate approaches to public and patient involvement in childhood disability research, and to determine whether methods for involving non- disabled CYP in research could allow disabled CYP to participate to the same extent.(Allsop et al. 2010) Furthermore, the quality of evidence in this review is low, thus limiting the conclusions that can be drawn. More effective PPI reporting and more robust methods of assessing the impact of involvement are needed.

\section{Acknowledgements}

The work was supported by the NIHR Collaboration for Leadership in Applied Health Research and Care of the South West Peninsula (PenCLAHRC), and the charity Cerebra who support PenCRU. The views and opinions expressed in this paper are those of the authors and not necessarily those of the NHS, the NIHR, the Department of Health, or Cerebra.

We are grateful to members of the parent advisory group for this project, in particular Tricia Stone and Antonia East for their help with website screening. We would like to thank the members of the PenCRU Family Faculty for their help and involvement in producing this systematic review. Their insights and opinions were invaluable at key stages in the review.

\section{Key messages}

1. The quality of evidence concerning involvement is low, and involvement of DCYP is generally under reported.

2. There was a lack of evidence about impacts of involvement, with most reported impacts based on authors' opinions rather than data.

3. More effective communication methods need to be developed to support the involvement of those who use non-verbal methods of communication.

4. A range of flexible methods should be available to support the involvement of DCYP, enabling them to maintain power and control over how and when they are involved. 
5. There remains much scope for methodological research to inform appropriate approaches to public and patient involvement in childhood disability research 
Allsop, M. J., Holt, R. J., Levesley, M. C. and Bhakta, B. (2010) 'The engagement of children with disabilities in health-related technology design processes: identifying methodology', Disability \& Rehabilitation Assistive Technology, 5(1), 1-13.

Barker, J. and Weller, S. (2003) '"Is it fun?" developing children centred research methods.', International Journal of Sociology and Social Policy., 23(1/2), 33-58.

Beresford, B. (2012) 'Working on Well-Being: Researchers' Experiences of a Participative Approach to Understanding the Subjective Well-Being of Disabled Young People', Children \& Society, 26(3), 234-240.

Beresford, B. (2012) 'Working on well-being: researchers' experiences of a participative approach to understanding the subjective well-being of disabled young people. ', Children \& Society., 26, 234-240.

Boote, J. Wong, R. and Booth, A. (2012) '"Talking the talk or walking the walk?" A bibliometric review of the literature on public involvement in health research published etween 1995 and 2009'. Health Expect, Oct 4 doi: 10.1111/hex.12007

Cavet, J. and Sloper, P. (2004) 'Participation of disabled children in individual decisions about their lives and in public decisions about service development', Children \& Society, 18(4), 278-290.

Clavering, E. K. and McLaughlin, J. (2010a) 'Children's participation in health research: from objects to agents?', Child Care Health Dev, 36(5), 603-11.

Clavering, E. K. and McLaughlin, J. (2010b) 'Children's participation in health research: from objects to agents?', Child: Care, Health \& Development, 36(5), 603-11.

Coad J and Evans R (2008) 'Reflections on practical approaches to involving children and young people in the data analysis process.', Children \& Society, 22, 41-52.

Coad, J. E. and Shaw, K. L. (2008) 'Is children's choice in health care rhetoric or reality? A scoping review', J Adv Nurs, 64(4), 318-27.

Commission, E. a. H. R. (1995) 'What is the definition of disability?', [online], available: http://www.equalityhumanrights.com/advice-and-guidance/your-rights/disability/ [accessed $21^{\text {st }}$ July 2013]

Critical Appraisal Skills Programme (CASP). CASP qualitative checklist: 10 questions to help you make sense of qualitative research. [online], available: 
http://media.wix.com/ugd/dded87_951541699e9edc71ce66c9bac4734c69.pdf [accessed $15^{\text {th }}$ July 2013]

Curtin, C. (2001) 'Eliciting children's voices in qualitative research', Am J Occup Ther, 55(3), 295-302.

Delman, J. (2012) 'Participatory action research and young adults with psychiatric disabilities', Psychiatric Rehabilitation Journal, 35(3), 231-4.

Germain R (2004) 'An exploratory study using cameras and talking mats to access the views of young people with learning disabilities on their out of school activities. ', British Journal of Learning Disabilities., 32, 170-174.

INVOLVE (2013) 'Approaches to public involvement in research', [online], available: http://www.invo.org.uk/posttyperesource/approaches-to-public-involvement/ [accessed $2^{\text {nd }}$ July 2013]

Kembhavi, G. and Wirz, S. (2009) 'Engaging adolescents with disabilities in research', ALTER European Journal of Disability Research / Revue Européenne de Recherche sur le Handicap, 3(3), 286-296.

Kirby, P. (2004) A guide to actively involving young people in research: for researchers, research commissioners and managers, London: INVOLVE.

Kirk, S. (2007) 'Methodological and ethical issues in conducting qualitative research with children and young people: a literature review', Int J Nurs Stud, 44(7), 1250-60.

Lightfoot, J. and Sloper, P. (2003) 'Having a say in health: involving young people with a chronic illnessor physical disability in local health services development', Children and Society, 17(4), 277-290.

McHugh, C., Bailey, S., Shilling, V. and Morris, C. (2013) 'Meeting the information needs of families of children with chronic health conditions', Phys Occup Ther Pediatr, 33(3), 265-70.

Milnes, L. J., McGowan, L., Campbell, M. and Callery, P. (2012) 'Developing an intervention to promote young people's participation in asthma review consultations with practice nurses', Journal of Advanced Nursing, 69(1), 91-101.

Mogensen, L. (2011) 'I want to be me' : learning from teenagers diagnosed with autism using collaborative, participatory research. Doctor of Philosophy (PhD), University of Western Sydney, Australia., unpublished thesis

Morris, C., Shilling, V., McHugh, C. and Wyatt, K. (2011) 'Why it is crucial to involve families in all stages of childhood disability research', Dev Med Child Neurol, 53(8), 769-71. 
Morris, J. (2003) 'Including all children: finding out about the experiences of children with communication and/or cognitive impairments', Children \& Society, 17(5), 337-348.

Morris J (2003) 'Including All Children: Finding out about the experiences of children with communication and/or cognitive impairments. ', Children \& Society, 17, 337-348.

Noyes, J. P., Williams, A., Allen, D., Brocklehurst, P., Carter, C., Gregory, J. W., Jackson, C., Lewis, M., Lowes, L., Russell, I. T., Rycroft-Malone, J., Sharp, J., Samuels, M., Edwards, R. T. and Whitaker, R. (2010) 'Evidence into practice: evaluating a child-centred intervention for diabetes medicine management. The EPIC Project', BMC Pediatrics, 10, 70.

Shaw, C., Brady, L. and Davey, C. (2011) Guidelines for research with children and young people, London: National Children's Bureau.

Sloper, P. and Lightfoot, J. (2003) 'Involving disabled and chronically ill children and young people in health service development', Child: Care, Health \& Development, 29(1), 15-20.

Staniszewska, S., Brett, J., Mockford, C. and Barber, R. (2011) 'The GRIPP checklist: strengthening the quality of patient and public involvement reporting in research', Int J Technol Assess Health Care, 27(4), 391-9.

Street, C. and Herts, B. (2005) Putting Participation into Practice, London: YoungMinds.

Tisdall, E. K. M. (2012) 'The challenge and challenging of childhood studies? Learning from disability studies and research with disabled children.', Children \& Society, 26, 181-191.

Turner, C. (2003) 'Are you listening? What disabled children and young people in Wales think about the services they use'. Barnardos [online] available: http://www.barnardos.org.uk/are-youlistening-what-disabled-children-and-young-people-in-wales-think-about-the-services-theyuse/publication-view.jsp?pid=PUB-1384 [accessed $27^{\text {th }}$ July 2013]

Vaughn, L. Wagner, E. and Jacquez, F. 'A review of community-based participatory research in child health'. MCN Am J Matern Child Nurs, 38(1), 48-53.

Veinot, T. C., Flicker, S. E., Skinner, H. A., McClelland, A., Saulnier, P., Read, S. E. and Goldberg, E. (2006) '"Supposed to make you better but it doesn't really": HIV-positive youths' perceptions of HIV treatment', J Adolesc Health, 38(3), 261-7.

VIPER (2012a) The VIPER project: what the qualitative research told us. [online] Available at: http://viper.councilfordisabledchildren.org.uk/resources/viper-project-reports/ (last accessed 1 August2013) 
VIPER (2012b) The VIPER project: what we found. [online]. Availableat:

http://viper.councilfordisabledchildren.org.uk/resources/viper-project-reports/ (last accessed 1 August 2013)

VIPER (2013) The VIPER website. online]. Available at:

http://viper.councilfordisabledchildren.org.uk/resources/viper-project-reports/ (last accessed 1 August 2013).

Watson, D., Abbot, D., Townsley, R. (2007) 'Listen to me, too! Lessons from involving children with complex healthcare needs in research about multi-agency services', Child Care Health Dev, 33(1), 9095 
Table 1: documents identified for inclusion in the reivew

\begin{tabular}{|c|c|c|c|c|}
\hline $\begin{array}{l}\text { Reference } \\
\text { (country) }\end{array}$ & $\begin{array}{l}\text { Type of } \\
\text { document }\end{array}$ & Aim of document & $\begin{array}{l}\text { Does it report an example of } \\
\text { involvement in health } \\
\text { research? }\end{array}$ & $\begin{array}{l}\text { Were DCYP involved in } \\
\text { producing this document? }\end{array}$ \\
\hline $\begin{array}{l}\text { Allsop et al } \\
(2010) \\
\text { (UK) }\end{array}$ & Review & $\begin{array}{l}\text { Literature review that aimed to identify research } \\
\text { methodology suitable for involving DCYP in the design } \\
\text { of healthcare technology. Includes recommendations } \\
\text { for involvement. }\end{array}$ & No & No \\
\hline $\begin{array}{l}\text { Beresford (2012) } \\
\text { (UK) }\end{array}$ & $\begin{array}{l}\text { Original } \\
\text { research }\end{array}$ & $\begin{array}{l}\text { Reporting involvement with a group of DCYP on a } \\
\text { project concerning perspectives of subjective well } \\
\text { being. Key strategies for involvement are presented. }\end{array}$ & Yes & No \\
\hline $\begin{array}{l}\text { Cavet and Sloper } \\
\text { (2004) } \\
\text { (UK) }\end{array}$ & Review & $\begin{array}{l}\text { Review of literature concerning the involvement of } \\
\text { DCYP in health service development. Includes a } \\
\text { number of recommendations. }\end{array}$ & No & No \\
\hline $\begin{array}{l}\text { Clavering and } \\
\text { McLaughlin } \\
\text { (2010) } \\
\text { (UK) }\end{array}$ & Review & $\begin{array}{l}\text { A literature review exploring ways in which DCYP have } \\
\text { been involved in research to identify strengths and } \\
\text { weaknesses. Only some parts specific to the } \\
\text { involvement of DCYP. }\end{array}$ & No & No \\
\hline $\begin{array}{l}\text { Delman (2012) } \\
\text { (USA) }\end{array}$ & Review & $\begin{array}{l}\text { Literature review describing key principles for } \\
\text { engaging CYP with psychiatric disabilities in research, } \\
\text { based on author's experience. }\end{array}$ & Yes & No \\
\hline $\begin{array}{l}\text { Kembhavi and } \\
\text { Wirz (2009) } \\
\text { (UK) }\end{array}$ & Review & $\begin{array}{l}\text { Literature review of methods for involving disabled } \\
\text { adolescents in research, and advantages and } \\
\text { disadvantages of these methods. }\end{array}$ & No & No \\
\hline $\begin{array}{l}\text { Kirby (2004) } \\
\text { (UK) }\end{array}$ & Guideline & $\begin{array}{l}\text { Guidance on involvement of CYP in research. Some } \\
\text { points focussed on DCYP. }\end{array}$ & No & Yes \\
\hline $\begin{array}{l}\text { Lightfoot and } \\
\text { Sloper (2003) } \\
\text { (UK) }\end{array}$ & $\begin{array}{l}\text { Original } \\
\text { research }\end{array}$ & $\begin{array}{l}\text { Gathered views of DCYP who had been involved in } \\
\text { health services development. Aimed to identify } \\
\text { acceptable approaches to involvement, from the } \\
\text { DCYPs' perspectives. }\end{array}$ & Yes & No \\
\hline Milnes (2012) & Original & Aimed to develop a pre-consultation guide for young & Yes & No \\
\hline
\end{tabular}




\begin{tabular}{|c|c|c|c|c|}
\hline $\begin{array}{l}\text { Mogensen (2011) } \\
\text { (Australia) }\end{array}$ & $\begin{array}{l}\text { Original } \\
\text { research }\end{array}$ & $\begin{array}{l}\text { Used a 'collaborative participatory approach' to } \\
\text { involve DCYP in deciding how research would be } \\
\text { carried out. These young people were also } \\
\text { interviewed for the study. }\end{array}$ & Yes & No \\
\hline $\begin{array}{l}\text { Morris (2003) } \\
\text { (UK) }\end{array}$ & Review & $\begin{array}{l}\text { Review of recommendations to gather the views of } \\
\text { DCYP, based on author's experiences. }\end{array}$ & No & No \\
\hline $\begin{array}{l}\text { Noyes (2010) } \\
\text { (UK) }\end{array}$ & $\begin{array}{l}\text { Original } \\
\text { research }\end{array}$ & $\begin{array}{l}\text { Involved DCYP in the design of diabetes control } \\
\text { materials for children. }\end{array}$ & Yes & No \\
\hline $\begin{array}{l}\text { Shaw et al (2011) } \\
\text { (UK) }\end{array}$ & Guideline & $\begin{array}{l}\text { Guidance on involvement of children in research, both } \\
\text { as participants and as partners. DCYP not main focus; } \\
\text { some sections address specific challenges of involving } \\
\text { this group. }\end{array}$ & No & No \\
\hline $\begin{array}{l}\text { Sloper and } \\
\text { Lightfoot (2003) } \\
\text { (UK) }\end{array}$ & $\begin{array}{l}\text { Original } \\
\text { research }\end{array}$ & $\begin{array}{l}\text { Investigates the extent and nature of involvement of } \\
\text { DCYP in health service development. }\end{array}$ & Yes & No \\
\hline $\begin{array}{l}\text { Street and Herts } \\
(2004) \\
\text { (UK) }\end{array}$ & Guideline & $\begin{array}{l}\text { Guidance on involving DCYP with mental health } \\
\text { illness, primarily for staff working in CAMHS. Draws on } \\
\text { authors' experience. }\end{array}$ & No & No \\
\hline $\begin{array}{l}\text { Turner (2003) } \\
\text { (UK) }\end{array}$ & Report & $\begin{array}{l}\text { Report about what DCYP in Wales think about the } \\
\text { services they use. DCYP were involved in the study. }\end{array}$ & Yes & No \\
\hline $\begin{array}{l}\text { Vaughn et al } \\
\text { (2013) } \\
\text { (USA) }\end{array}$ & Review & $\begin{array}{l}\text { Literature review about involving CYP in research; } \\
\text { three of } 34 \text { studies identified by the review had } \\
\text { involved DCYP. }\end{array}$ & Yes & No \\
\hline $\begin{array}{l}\text { Veinot }(2006) \\
\text { (Canada) }\end{array}$ & $\begin{array}{l}\text { Original } \\
\text { research }\end{array}$ & $\begin{array}{l}\text { Mixed methods research study to investigate HIV } \\
\text { positive youths' perceptions and experiences of } \\
\text { antiretroviral treatment. DCYP were included in the } \\
\text { research team for this project. }\end{array}$ & Yes & No \\
\hline
\end{tabular}




\begin{tabular}{|c|c|c|c|c|}
\hline $\begin{array}{l}\text { VIPER: project } \\
\text { website (UK) }\end{array}$ & $\begin{array}{l}\text { Other: } \\
\text { website }\end{array}$ & $\begin{array}{l}\text { Project website, includes information about the } \\
\text { involvement of DCYP in the project. }\end{array}$ & Yes & Yes \\
\hline $\begin{array}{l}\text { VIPER: what the } \\
\text { qualitative } \\
\text { research told us } \\
\text { (2012) (UK) }\end{array}$ & Report & $\begin{array}{l}\text { Report produced in partnership with DCYP. Includes } \\
\text { information about involvement of DCYP in producing } \\
\text { the report. }\end{array}$ & Yes & Yes \\
\hline $\begin{array}{l}\text { VIPER: what we } \\
\text { found (2012) } \\
\text { (UK) }\end{array}$ & Report & $\begin{array}{l}\text { Report produced in partnership with DCYP. Includes } \\
\text { information about involvement of DCYP in producing } \\
\text { the report. }\end{array}$ & Yes & Yes \\
\hline $\begin{array}{l}\text { Watson et al } \\
\text { (2007) } \\
\text { (UK) }\end{array}$ & $\begin{array}{l}\text { Original } \\
\text { research }\end{array}$ & $\begin{array}{l}\text { Included a reference group of two DCYP in } \\
\text { investigating the involvement of DCYP in multi-agency } \\
\text { services, }\end{array}$ & Yes & No \\
\hline
\end{tabular}


Table 2: Examples of projects that have involved disabled children and young people in the research process.

\begin{tabular}{|c|c|c|c|c|c|c|c|}
\hline Reference & Aim of involvement & $\begin{array}{l}\text { Number of } \\
\text { DCYP }\end{array}$ & $\begin{array}{l}\text { Ages of } \\
\text { DCYP }\end{array}$ & $\begin{array}{l}\text { Condition of } \\
\text { DCYP }\end{array}$ & $\begin{array}{l}\text { Source of funding } \\
\text { for involvement }\end{array}$ & $\begin{array}{l}\text { Methods of recruitment and } \\
\text { selection }\end{array}$ & Activities undertaken by DCYP \\
\hline $\begin{array}{l}\text { Beresford } \\
2012\end{array}$ & $\begin{array}{l}\text { A regular discussion and consultation } \\
\text { group of DCYP that meets twice a term at } \\
\text { a special school. DCYP work with the } \\
\text { research team on research projects. }\end{array}$ & $8-10$ & $14-18$ & $\begin{array}{l}\text { Learning } \\
\text { disabilities } \\
\text { and/or physical } \\
\text { impairments. } \\
\end{array}$ & Not reported & $\begin{array}{l}\text { Recruited through special } \\
\text { school. Head teacher selected } \\
\text { pupils who were invited to join } \\
\text { the group. }\end{array}$ & Not reported \\
\hline $\begin{array}{l}\text { Delman } \\
2012\end{array}$ & $\begin{array}{l}\text { To involve a group of DCYP in a project } \\
\text { about the service preferences of } \\
\text { transition age youth. }\end{array}$ & $\begin{array}{l}\text { Not } \\
\text { reported }\end{array}$ & $\begin{array}{l}\text { Transition } \\
\text { age } \\
\text { (typically } \\
\text { around 18) }\end{array}$ & $\begin{array}{l}\text { Psychiatric } \\
\text { conditions }\end{array}$ & Not reported & Not reported & $\begin{array}{l}\text { Reviewed interview guides for } \\
\text { interviewing DCYP. Contributed to policy } \\
\text { recommendations to be included in the } \\
\text { final report. Presented findings to local } \\
\text { authority committees. }\end{array}$ \\
\hline $\begin{array}{l}\text { Lightfoot } \\
\text { and Sloper } \\
2003\end{array}$ & $\begin{array}{l}\text { DCYP advised at key stages in a project } \\
\text { which aimed to identify factors which } \\
\text { can support the involvement of DCYP in } \\
\text { health service development and prepare } \\
\text { guidelines for NHS staff. }\end{array}$ & Two & $\begin{array}{l}\text { Not } \\
\text { reported }\end{array}$ & Not reported & $\begin{array}{l}\text { Department of } \\
\text { Health 'Health in } \\
\text { Partnership' } \\
\text { research initiative }\end{array}$ & $\begin{array}{l}\text { Recruited from a local youth } \\
\text { forum }\end{array}$ & $\begin{array}{l}\text { DCYP involved in the design of } \\
\text { recruitment materials, interview topic } \\
\text { guides, interpretation of results, planning } \\
\text { a workshop for young participants and } \\
\text { staff at which draft guidelines would be } \\
\text { reviewed and finalised. }\end{array}$ \\
\hline $\begin{array}{l}\text { Milnes et al } \\
2012\end{array}$ & $\begin{array}{l}\text { Develop evidence-based pre-consultation } \\
\text { guide for YP prior to asthma review } \\
\text { appointment. Aimed to increase the } \\
\text { acceptability of the guide by involving YP } \\
\text { with asthma in the design. }\end{array}$ & Six & $16-18$ & Asthma & $\begin{array}{l}\text { NIHR pre-doctoral } \\
\text { fellowship }\end{array}$ & $\begin{array}{l}\text { Volunteers responded to an } \\
\text { advert placed in 'Bright Minds' }\end{array}$ & $\begin{array}{l}\text { DCYP worked with professionals on the } \\
\text { expert panel. They communicated with } \\
\text { the team by email and social media. They } \\
\text { contributed to the criteria and statements } \\
\text { in the guide. }\end{array}$ \\
\hline $\begin{array}{l}\text { Mogensen } \\
2011\end{array}$ & $\begin{array}{l}\text { DCYP were involved in deciding how the } \\
\text { research would be carried out. They } \\
\text { were also participants in this study. }\end{array}$ & Six & $10-16$ & ASD & Not reported & $\begin{array}{l}\text { Adverts were placed on autism } \\
\text { websites and in school } \\
\text { newsletters. Parents had to } \\
\text { respond on behalf of the DCYP. }\end{array}$ & $\begin{array}{l}\text { DCYP were involved in deciding where } \\
\text { interviews were going to take place, who } \\
\text { would be present at the interview, the } \\
\text { topics to be covered in the interview, } \\
\text { communication methods during the } \\
\text { interview, and how they wanted to give } \\
\text { and receive feedback. }\end{array}$ \\
\hline $\begin{array}{l}\text { Noyes et al } \\
2010\end{array}$ & $\begin{array}{l}\text { The study aimed to involve DCYP in } \\
\text { developing a range of age appropriate } \\
\text { diabetes control documents including } \\
\text { diaries and information packs. }\end{array}$ & $\begin{array}{l}\text { Not } \\
\text { reported }\end{array}$ & $\begin{array}{l}\text { Not } \\
\text { reported }\end{array}$ & Diabetes & $\begin{array}{l}\text { NIHR delivery and } \\
\text { organisation } \\
\text { programme }\end{array}$ & $\begin{array}{l}\text { CYP with diabetes volunteered } \\
\text { at fun days organised by } \\
\text { diabetes charities and support } \\
\text { groups. The opportunity was } \\
\text { also advertised in support and } \\
\text { network newsletters. }\end{array}$ & $\begin{array}{l}\text { DCYP could get involved in web based } \\
\text { activities or comment on drafts at fun } \\
\text { days. They commented on artwork, } \\
\text { format, size and types of information in } \\
\text { the documents. }\end{array}$ \\
\hline $\begin{array}{l}\text { VIPER } \\
\text { project }\end{array}$ & $\begin{array}{l}\text { To involve a group of DCYP in research } \\
\text { about decision making in local services. }\end{array}$ & 16 & $12-21$ & $\begin{array}{l}\text { Various } \\
\text { conditions }\end{array}$ & Big Lottery Fund & $\begin{array}{l}\text { Recruitment and selection } \\
\text { process involved an application } \\
\text { form with seven questions, } \\
\text { asking about interests, } \\
\text { experience, and opinions of } \\
\text { DCYP having a say. }\end{array}$ & $\begin{array}{l}\text { Involved in survey and qualitative } \\
\text { research. Activities included: contributing } \\
\text { to design of research, designing topic } \\
\text { guides and questions for interview, } \\
\text { carrying out interviews and focus groups, } \\
\text { designing consent forms, data coding and }\end{array}$ \\
\hline
\end{tabular}




\begin{tabular}{|c|c|c|c|c|c|c|c|}
\hline Reference & Aim of involvement & $\begin{array}{l}\text { Number of } \\
\text { DCYP }\end{array}$ & $\begin{array}{l}\text { Ages of } \\
\text { DCYP }\end{array}$ & $\begin{array}{l}\text { Condition of } \\
\text { DCYP }\end{array}$ & $\begin{array}{l}\text { Source of funding } \\
\text { for involvement }\end{array}$ & $\begin{array}{l}\text { Methods of recruitment and } \\
\text { selection }\end{array}$ & Activities undertaken by DCYP \\
\hline & & & & & & & analysis, preparing reports. \\
\hline $\begin{array}{l}\text { Veinot et al } \\
2006\end{array}$ & $\begin{array}{l}\text { Developed research design and } \\
\text { instruments. Also involved in } \\
\text { implementation, analysis and } \\
\text { dissemination. Data were coded by two } \\
\text { trained youth community researchers. } \\
\text { Random checks of these data were } \\
\text { carried out to ensure accuracy. }\end{array}$ & $\begin{array}{l}\text { Varied, with } \\
\text { a core } \\
\text { group of } \\
\text { four (S. } \\
\text { Flicker, } \\
\text { pers. } \\
\text { comm.) }\end{array}$ & $\begin{array}{l}\text { Not } \\
\text { reported }\end{array}$ & HIV & $\begin{array}{l}\text { Ontario HIV } \\
\text { Treatment } \\
\text { Network. }\end{array}$ & $\begin{array}{l}\text { Young people were recruited } \\
\text { from a community group ( } \mathrm{S} . \\
\text { Flicker, pers. comm.) }\end{array}$ & $\begin{array}{l}\text { Developed research design and } \\
\text { instruments. Also involved in } \\
\text { implementation, analysis and } \\
\text { dissemination. Data were coded by two } \\
\text { trained youth community researchers. } \\
\text { Random checks of these data were } \\
\text { carried out to ensure accuracy. }\end{array}$ \\
\hline $\begin{array}{l}\text { Watson et } \\
\text { al } 2007\end{array}$ & $\begin{array}{l}\text { Involved two DCYP in developing a } \\
\text { methodology for consulting with DCYP, } \\
\text { as part of a research project about multi- } \\
\text { agency services. }\end{array}$ & Two & $\begin{array}{l}\text { Not } \\
\text { reported }\end{array}$ & $\begin{array}{l}\text { Not reported; } \\
\text { 'complex } \\
\text { healthcare } \\
\text { needs' }\end{array}$ & $\begin{array}{l}\text { The Big Lottery } \\
\text { Fund and the } \\
\text { Family Fund. }\end{array}$ & $\begin{array}{l}\text { Advertisement placed in parent } \\
\text { magazine (D. Watson, pers. } \\
\text { comm.) }\end{array}$ & $\begin{array}{l}\text { Used disposable cameras to capture } \\
\text { important things in their lives, advised } \\
\text { researchers on issues that affect them. }\end{array}$ \\
\hline
\end{tabular}



Figure 1: selection of studies

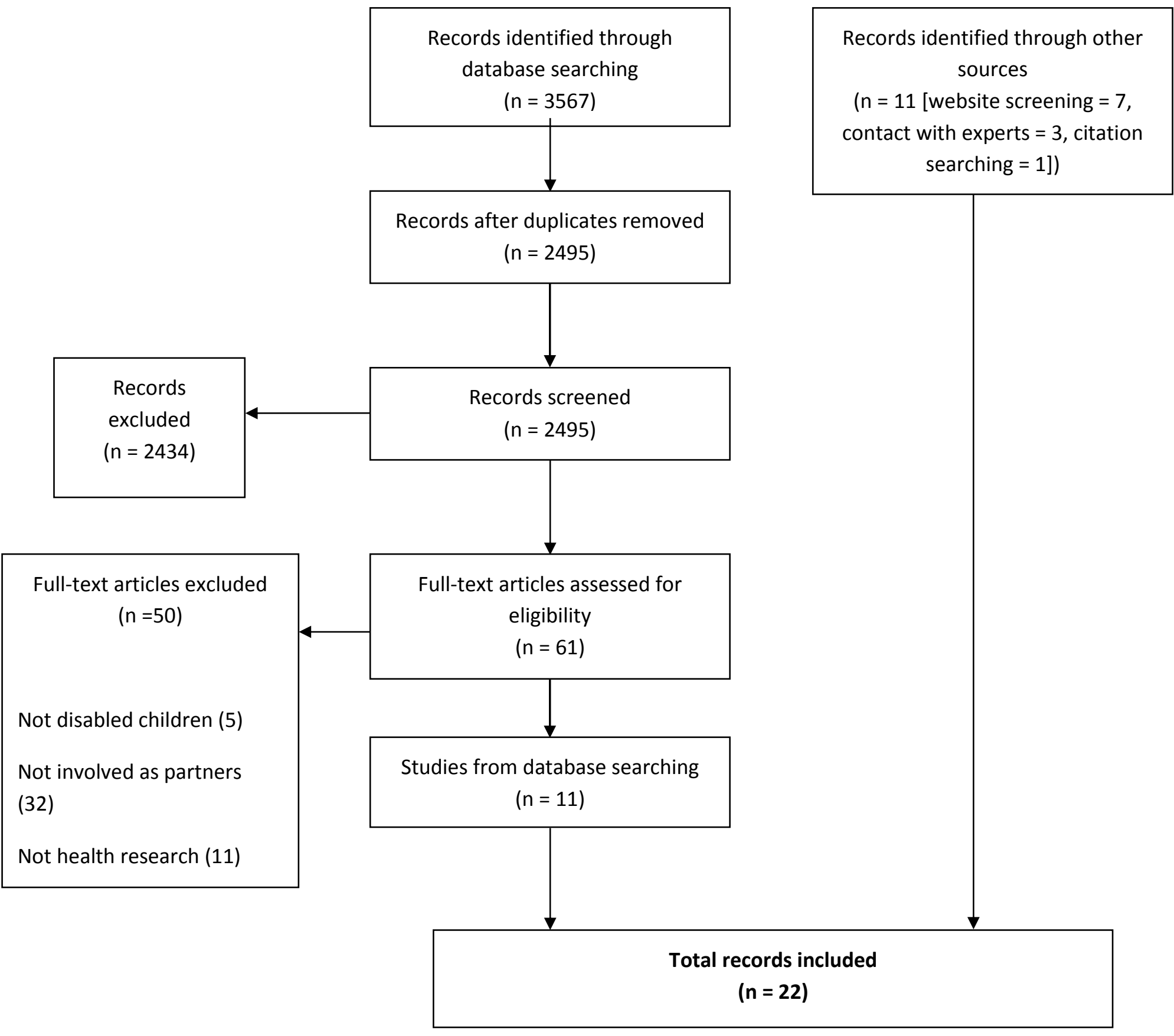


Figure 2: potential positive and negative impacts of involvement on disabled children and young people, and on research.

Potential positive impacts of involvement on DCYP

- Increased confidence ${ }^{1-3}$

- Increased self-esteem ${ }^{3,5,6}$

- Gaining new skills and experiences $1,2,6$

- Greater responsibility and independence ${ }^{2,3,6}$

- Opportunity to socialise with peers ${ }^{3,6,8}$

- Enhanced knowledge of and access to decision making 6

- $\quad$ Being empowered ${ }^{6,7}$

- Positive changes in expectations of being involved ${ }^{8}$

- An opportunity to share frustrations and appreciations ${ }^{6,9}$

- Knowing that their views and opinions are respected and valued ${ }^{1,3,7}$

- Knowing that they can make a difference ${ }^{3,6,7}$

- Knowing that their efforts may help other young people ${ }^{3}$

Potential negative impacts of involvement on DCYP

- Learning about other's lives and risk taking behaviours may cause distress ${ }^{10}$

- Increased awareness of differences between how they view themselves and how others view then ${ }^{10}$

- Perceptions of tokenism may result in disillusionment and reduced benefits. ${ }^{1,11}$

- It may not be possible to maintain confidentiality in meetings ${ }^{6}$

- May initially feel intimidated by unfamiliar people and working environment ${ }^{2,6}$

- May lose confidence or interest if faced with challenges they feel they cannot face ${ }^{2}$
Potential positive impacts of involvement on research

- Improved appropriateness and quality of research $2,4,6,8,12$

- Prioritisation of research questions that are relevant and important to DCYP2,6,13

- More age appropriate and accessible recruitment and advertising materials $\mathrm{s}^{8,14}$

- Study protocols and interventions that are more acceptable to other DCYP ${ }^{4}$

- Greater credibility and interest in studies ${ }^{8}$

- Positive contribution to data collection, especially when DCYP interview others in their peer group. ${ }^{2,15}$

- A unique perspective during data analysis, particularly on data collected from other young people. ${ }^{6,15}$

- Successful contribution to interview transcript coding $^{16}$

Potential negative impacts of involvement on research

- Greater resources, staff skills and training are required to facilitate involvement ${ }^{1,15,17}$

- Research process may take longer ${ }^{6,10,15}$

1 Cavet and Sloper 2004; 2 Delman 2012; 3 Lightfoot and Sloper 2003; 4 Milnes et al 2013; 5 VIPER 2013; 6 Street and Herts 2005; 7 Mogensen 2010; 8 VIPER 2012b; 9 Sloper and Lightfoot 2003; 10 Beresford 2012; 11 Allsop et al 2010; 12 Clavering and McLaughlin 2010b; 13 Morris 2003; 14 Noyes et al 2010; 15 VIPER 2012a; 16 Veinot et al 2006; 17 Kirby 2004. 


\section{Appendix 1: Search Strategies}

\section{Database(s): MEDLINE(R)}

Host: Ovid

Data parameters: 1946 to March Week 42013

Date searched: $3 / 4 / 13$

Searched by: $\mathrm{SBr}$

Strategy checked by: SB, CM, KB

Search strategy:

1. (child* or "young person*" or "young people" or teenage* or adolescent* or "young adult*").ti,ab.

2. (participat* or involv* or engag* or consult* or partner* or collaborat* or advisory or perspective*).ti,ab.

3. ("cerebral palsy" or epilep* or autis* or "down* syndrome").ti,ab.

4. ((child* or "young person*" or "young people" or teenage* or adolescent* or "young adult*") adj2 (participat* or involv* or engag* or consult* or partner* or collaborat* or advisory or perspective*)).ti,ab.

5. (("cerebral palsy" or epilep* or autis* or "down* syndrome") adj3 ((child* or "young person*" or "young people" or teenage* or adolescent* or "young adult*") adj2 (participat* or involv* or engag* or consult* or partner* or collaborat* or advisory or perspective*))).ti,ab.

6. (participat* or involv* or engag* or consult* or partner* or collaborat* or advisory or perspective*).kw.

7. Patient Participation/

8. Consumer Participation/

9. or $/ 6-8$

10. (disab* or "chronic health" or "long term condition*" or "learning disorder*" or "learning difficult*").ti,ab.

11. (disab* or "chronic health" or "long term condition*" or "learning disorder*" or "learning difficult*" or "cerebral palsy" or epilep* or autis* or "down* syndrome").kw.

12. exp disabled persons/

13. exp Intellectual Disability/

14. exp learning disorders/

15. Cerebral Palsy/

16. exp Epilepsy/

17. Autistic Disorder/

18. Down Syndrome/

19. or $/ 10-18$

20. 1 and 9 and 19

21. 4 and 19

22. 5 or 20 or 21

23. limit 22 to (english language and $y r=" 1990$-Current")

Notes: $\mathrm{n} / \mathrm{a}$

Hits $=1024$ 


\section{Database(s): MEDLINE(R) In-Process \& Other Non-Indexed Citations}

Host: Ovid

Data parameters: April 04, 2013

Date searched: 4/4/13

Searched by: $\mathrm{SBr}$

Search strategy:

1. (child* or "young person*" or "young people" or teenage* or adolescent* or "young adult*").ti,ab.

2. (participat* or involv* or engag* or consult* or partner* or collaborat* or advisory or perspective*).ti,ab.

3. ("cerebral palsy" or epilep* or autis* or "down* syndrome").ti,ab.

4. ((child* or "young person*" or "young people" or teenage* or adolescent* or "young adult*") adj2 (participat* or involv* or engag* or consult* or partner* or collaborat* or advisory or perspective*)).ti,ab.

5. (("cerebral palsy" or epilep* or autis* or "down* syndrome") adj3 ((child* or "young person*" or "young people" or teenage* or adolescent* or "young adult*") adj2 (participat* or involv* or engag* or consult* or partner* or collaborat* or advisory or perspective*))).ti,ab.

6. (disab* or "chronic health" or "long term condition*" or "learning disorder*" or "learning difficult*").ti,ab.

7. 4 and 6

8. 5 or 7

Notes: $\mathrm{n} / \mathrm{a}$

Hits $=54$

\section{Database(s): ASSIA}

Host: ProQuest

Data parameters: $\mathrm{n} / \mathrm{a}$

Date searched: $4 / 4 / 13$

Searched by: SBr

Search strategy: The strategy is in three parts owing to limitations of running large strategies in ASSIA via the ProQuest interface.

((AB,TI(child* OR "young person*" OR "young people" or teenage* OR adolescent* OR "young adult*") NEAR/2 AB,TI(participat* OR involv* OR consult* OR engag* OR partner* OR collaborat* OR advisory OR perspective*)) NEAR/3 TI,AB("cerebral palsy" or epilep* or autis* or "down* syndrome"))

Notes: Limited to 1990-current and English language only

Hits $=65$

(AB,TI(child* OR "young person*" OR "young people" OR teenage* OR adolescent* OR "young adult*") AND (SU.EXACT("Patient participation" OR "Consumer participation") OR IF(participat* OR involv* OR consult* OR engag* OR partner* OR collaborat* OR advisory OR perspective*)) AND (TI,AB(disab* or "chronic health" or "long term condition*" or "learning disorder*" or "learning difficult*") OR IF(disab* or "chronic health" or "long term condition*" or "learning disorder*" or "learning difficult*" or "cerebral palsy" or epilep* or autis* or "down* syndrome") OR 
(SU.EXACT("Disabled people") OR SU.EXACT("Learning disabilities") OR SU.EXACT("Cerebral palsy") OR SU.EXACT("Epilepsy") OR SU.EXACT("Autism") OR SU.EXACT("Down's syndrome"))))

Notes: Limited to 1990-current and English language only

Hits $=966$

(AB,TI(child* OR "young person*" OR "young people" or teenage* OR adolescent* OR "young adult*") NEAR/2 AB,TI(participat* OR involv* OR consult* OR engag* OR partner* OR collaborat* OR advisory OR perspective*)) AND ((TI,AB(disab* or "chronic health" or "long term condition*" or "learning disorder*" or "learning difficult*") OR IF(disab* or "chronic health" or "long term condition*" or "learning disorder*" or "learning difficult*" or "cerebral palsy" or epilep* or autis* or "down* syndrome") OR (SU.EXACT("Disabled people") OR SU.EXACT("Learning disabilities") OR SU.EXACT("Cerebral palsy") OR SU.EXACT("Epilepsy") OR SU.EXACT("Autism") OR SU.EXACT("Down's syndrome"))))

Notes: Limited to 1990-current and English language only

Hits $=511$

Total hits $=1542$

\section{Database(s): CINAHL}

Host: EBSCO

Data parameters: $\mathrm{n} / \mathrm{a}$

Date searched: $3 / 4 / 13$

Searched by: $\mathrm{SBr}$

Search strategy:

1. TI(child* or "young person*" or "young people" or teenage* or adolescent* or "young adult*") OR AB(child* or "young person*" or "young people" or teenage* or adolescent* or "young adult*")

2. TI(participat* or involv* or engag* or consult* or partner* or collaborat* or advisory or perspective*) OR AB(participat* or involv* or engag* or consult* or partner* or collaborat* or advisory or perspective*)

3. TI("cerebral palsy" or epilep* or autis* or "down* syndrome") OR AB("cerebral palsy" or epilep* or autis* or "down* syndrome")

4. S1 N2 S2

5. (S1 N2 S2) N3 S3

6. (MH "Consumer Participation")

7. TI(disab* or "chronic health" or "long term condition*" or "learning disorder*" or "learning difficult*") OR AB(disab* or "chronic health" or "long term condition*" or "learning disorder*" or "learning difficult*")

8. (MH "Disabled+") or (MH "Learning Disorders")

9. (MH "Cerebral Palsy")

10. (MH "Epilepsy+")

11. (MH "Autistic Disorder")

12. (MH "Down Syndrome")

13. S7 OR S8 OR S9 OR S10 OR S11 OR S12

14. S1 AND S6 AND S13 
15. S4 AND S13

16. S5 OR S14 OR S15

17. S5 OR S14 OR S15

Notes: Limited to 1990-current and English language only

Hits $=918$

\section{Database(s): Cochrane (CDSR and DARE)}

Host: Cochrane Collaboration

Data parameters: CDSR=Issue 3 of 12, Mar 2013; DARE= Issue 1 of 4, Jan 2013

Date searched: 4/4/13

Searched by: $\mathrm{SBr}$

Search strategy:

1. (child* or "young person*" or "young people" or teenage* or adolescent* or "young adult*"):ti or (child* or "young person*" or "young people" or teenage* or adolescent* or "young adult*"):ab in Cochrane Reviews (Reviews and Protocols) and Other Reviews

2. (participat* or involv* or engag* or consult* or partner* or collaborat* or advisory or perspective*):ti or (participat* or involv* or engag* or consult* or partner* or collaborat* or advisory or perspective*):ab in Cochrane Reviews (Reviews and Protocols) and Other Reviews

3. ("cerebral palsy" or epilep* or autis* or "down* syndrome"):ti or ("cerebral palsy" or epilep* or autis* or "down* syndrome"):ab in Cochrane Reviews (Reviews and Protocols) and Other Reviews

4. \#1 near $3 \# 2$

5. (\#1 near/3 \#2) near/4 \#3

6. (participat* or involv* or engag* or consult* or partner* or collaborat* or advisory or perspective*):kw in Cochrane Reviews (Reviews and Protocols) and Other Reviews

7. MeSH descriptor: [Consumer Participation] explode all trees

8. $\# 6$ of \#7

9. (disab* or "chronic health" or "long term condition*" or "learning disorder*" or "learning difficult*"):ti or (disab* or "chronic health" or "long term condition*" or "learning disorder*" or "learning difficult*"):ab in Cochrane Reviews (Reviews and Protocols) and Other Reviews

10. (disab* or "chronic health" or "long term condition*" or "learning disorder*" or "learning difficult*" or "cerebral palsy" or epilep* or autis* or "down* syndrome"):kw in Cochrane Reviews (Reviews and Protocols) and Other Reviews

11. MeSH descriptor: [Disabled Persons] explode all trees

12. MeSH descriptor: [Intellectual Disability] explode all trees

13. MeSH descriptor: [Learning Disorders] explode all trees

14. MeSH descriptor: [Cerebral Palsy] this term only

15. MeSH descriptor: [Epilepsy] explode all trees

16. MeSH descriptor: [Autistic Disorder] this term only

17. MeSH descriptor: [Down Syndrome] explode all trees

18. \#9 or \#10 or \#11 or \#12 or \#13 or \#14 or \#15 or \#16 or \#17

19. $\# 1$ and $\# 8$ and $\# 18$

20. $\# 4$ and \#18

21. \#5 or \#19 or \#20 from 1990, in Cochrane Reviews (Reviews and Protocols) and Other Reviews 
Notes: Limited to 1990-current

Hits $=28($ CDSR $)$; 1(DARE)

\section{Totals}

\begin{tabular}{|l|l|}
\hline \multicolumn{1}{|c|}{ Database } & Hits \\
\hline MEDLINE & 1024 \\
\hline MEDLINE-in-Process & 54 \\
\hline ASSIA & 1542 \\
\hline CINAHL & 918 \\
\hline CDSR & 28 \\
\hline DARE & 1 \\
\hline Total & $\mathbf{3 5 6 7}$ \\
\hline Duplicate records & $\mathbf{1 0 7 1}$ \\
\hline Total Records to Screen & $\mathbf{2 4 9 6}$ \\
\hline
\end{tabular}


Appendix 2: children's, disability and child disability websites

1. UK children's charities

National Children's Bureau http://www.ncb.org.uk/

Barnados $\quad$ http://www.barnardos.org.uk/

Great Ormond Street Hospital http://www.gosh.org/gen/

Action for Children http://www.actionforchildren.org.uk/

UNICEF $\quad$ http://www.unicef.org.uk/

Save the Children http://www.savethechildren.org.uk/

2. UK disability charities

$\begin{array}{ll}\text { MenCap } & \underline{h t t p: / / w w w . m e n c a p . o r g . u k / ~} \\ \text { Scope } & \underline{h t t p: / / w w w . s c o p e . o r g . u k / ~} \\ \text { Ataxia } & \text { http://www.ataxia.org.uk/ } \\ \text { Spectrum } & \text { http://www.spectrumasd.org/ } \\ \text { QEF } & \text { http://qef.org.uk/ } \\ \text { The Disabilities Trust } & \text { http://www.thedtgroup.org/ } \\ \text { United response } & \underline{\text { http://www.unitedresponse.org.uk/ }} \\ \text { HFT } & \underline{\text { http://www.hft.org.uk/ }}\end{array}$

MIND - learning disability web resources $\quad$ http://www.mind.org.uk/mental health a-

z/8019 learning disability resources

Motivation http://www.motivation.org.uk/

Fitzroy $\quad$ http://www.fitzroy.org/

3. UK disabled children's charities

Whizz Kidz

Young Epilepsy

Phab

I Can (speech disabilities) http://www.ican.org.uk/ http://www.whizz-kidz.org.uk/

http://www.ncype.org.uk/

http://phab.org.uk/ 
Hope for children http://www.hope-for-children.org/

Variety http://www.variety.org.uk/

The Children's Trust http://www.thechildrenstrust.org.uk/

National Deaf Children's Society http://www.ndcs.org.uk/

Action for Kids $\quad$ http://www.actionforkids.org/

National Blind Childrens Society http://www.nbcs.org.uk/

Reach

http://www.reach.org.uk/

Lifeline4kids

http://www.lifeline4kids.org/

Look: national federation of families with visually impaired children http://www.look-uk.org/

European Academy of Childhood Disability http://www.eacd.org/

Kids $\quad$ http://www.kids.org.uk/

Tree of Hope $\quad$ http://www.treeofhope.org.uk/

New Life Foundation for Disabled Children http://www.newlifecharity.co.uk/

\section{National Associations}

$\underline{\text { RNIB }}$ http://www.rnib.org.uk/Pages/Home.aspx

British Deaf Association http://www.bda.org.uk/

National Autistic Society http://www.autism.org.uk/

National Disability Rights Network (USA) http://www.ndrn.org/index.php

\section{Regional disability charities/websites}

Capability Scotland http://www.capability-scotland.org.uk/

Update: disability info Scotland http://www.update.org.uk/

Sense Scotland http://www.sensescotland.org.uk/

Enable Scotland http://www.enable.org.uk/aboutus/Pages/default.aspx

Linking education and disability http://www.lead.org.uk/

For Scotland's Disabled Childrenhttp://www.fsdc.org.uk/

List of disability websites with some focus on Wales http://www.disabilitywales.org/links 
Learning Disability Wales $\quad$ http://www.learningdisabilitywales.org.uk/

Cedar foundation (Northern Ireland) http://www.cedar-foundation.org/

Disability Federation of Ireland http://www.disability-federation.ie/

Enable Ireland http://www.enableireland.ie/

National Disability Authority http://www.nda.ie/

6. Other suggestions from patient involvement meeting:

NASA http://www.nasa.gov/offices/education/programs/national/semaa/home/index.html

UN - 'Best practices for including persons with disabilities in all aspects of development efforts'.

See http://www.un.org/disabilities/documents/best practices publication 2011.pdf

7. Other websites to check

INVOLVE http://www.invo.org.uk/

Total 53 